\title{
Behavior rating and intelligence testing in primary school children exposed to multiple adverse experiences
}

\author{
Ebtissam M. Salah El-Din ${ }^{1}$, Manal A. Shehata ${ }^{1 *} \mathbb{D}$, Amany El-Wakkad ${ }^{2}$, Somaia Ismail ${ }^{3}$, Ehab M. Eid ${ }^{4}$, \\ Howida H. El-Gebaly ${ }^{4}$ and Alshimaa A. Elkhatib ${ }^{1}$
}

\begin{abstract}
Background: Early childhood frequent exposure to toxic stress such as abuse or neglect, parental substance abuse or parental mental illness, and violence can have a cumulative impact on the child's mental health. Therefore, the study aimed to assess the association between frequent exposures to family-related adverse experiences and the development of behavioral and cognitive impairment in a random sample of Egyptian primary school children.

Results: Witnessing household member treated violently was the most prevalent adversity in $90.4 \%$ of the studied students, followed by emotional neglect in $88.6 \%$. The highly exposed children were more likely to have below-average performance IQ, 2.5 times more than the exposed group $(P=0.03)$ [IQ score is considered average if it ranged 90-110 and below average if it ranged 70-89]. They were nearly 3 times at risk to develop behavioral problems $(P=0.003), 2.5$ times more likely to develop attention deficit $(P=0.02)$, and nearly 5 times more likely to develop externalizing behavior $(P<0.001)$ than their peers.
\end{abstract}

Conclusion: Early exposure to adverse experiences increases the child's vulnerability to attention deficit and externalizing behavior with negative impact on $\mathrm{IQ}$ scores especially performance IQ.

Keywords: Childhood adversity, Cognitive, Behavioral disturbances

\section{Background}

Adverse childhood experiences (ACEs) or childhood maltreatment indicates some of the major intensive causes of stress that a child possibly suffers early in life. These experiences include neglect, abuse, witnessing violence between parents or caregivers, different kinds of household dysfunction such as parental substance abuse or alcohol addiction, and peer or community violence. Studies showed that stress in childhood has life-long consequences for health and well-being, which could be explained by disruption of early brain development and compromising of immune and nervous systems [1].

History of early adverse life experiences has been linked to impairment of memory, concentration, and verbal ability in midlife [2]. Adverse childhood events

\footnotetext{
* Correspondence: dr_manalabdelkader@hotmail.com

${ }^{1}$ Department of Child Health, National Research Centre, 33 El-Bohouth Street (former El Tahrir St.), PO Box-12622, Giza, Cairo, Egypt

Full list of author information is available at the end of the article
}

have been associated with a greater risk of psychiatric disorders in adult life as well $[3,4]$, and it is likely to be an important determinant of mental ill-health [5]. This association was found significantly with anxiety, substance abuse, mood, and behavior disorders, either one of them or more than one simultaneously $[3,4,6]$.

Furthermore, adversity-related variables such as multiple exposure and age of exposure were found to be more important determinants of risk than the exposure itself [7]. The majority of the considered biological bases for these influencers is the glucocorticoid cascades hypothesis, where persistent stressor triggers long-lasting hyperactivity of the hypothalamic-pituitary-adrenal (HPA) axis [8], leading to hypercortisolemia and accompanied atrophy of the hippocampus, a main neural substrate for learning and memory [9]. In addition, it was evidenced that elevated glucocorticoids impair neuronal growth and survival [10].

Most research has focused on the consequences of early childhood adversities on physical and psychological 
health in adults and old age $[11,12]$. There is insufficient information about such effects during childhood and adolescence, which is an issue of potential clinical importance. The current study hypothesized that early exposure to multiple or recurrent life difficulties would adversely affect cognitive and behavioral characteristics of children.

Hence, the objective of this study was to assess the association between frequent exposure to family-related adverse experiences and the development of behavioral and cognitive impairment in a random sample of Egyptian primary school children.

\section{Methods}

The current study is a cross-sectional comparative study. Exposure to adverse childhood experiences was the main variable which classified children into two groups: exposed and non-exposed. Behavior and cognitive abilities were the outcomes compared in the two groups. The study was conducted along the period from April 2015 to December 2016.

\section{Calculation of sample size}

There is a shortage of large-scale, international research on the prevalence of negative life events which may constitute potential childhood adversity. Vanaelst et al. [13] found that $53.4 \%$ and $40.3 \%$ of the children experienced at least one familial and social adversities or negative life events in 8 European countries, but this prevalence has changed by region and age group. No previous studies have estimated the prevalence of childhood adversity in Egyptian primary school children, so we are guessing that $50 \%$ of the primary school children aged 7-11 years have a history of childhood adversity.

Sample size is calculated using the equation published by Dawson-Saunders and Trapp:

$$
\mathrm{n}=\frac{\mathrm{t} 2 \times \mathrm{p} \times(1-\mathrm{p})}{\mathrm{m} 2}
$$

where $n=$ required sample size, $t=$ confidence level at 95\% (standard value of 1.96), $p=$ estimated prevalence of the problem in the study area, and $m=$ margin of error at $5 \%$ (standard value of 0.05 ).

Therefore, to detect a true difference of $5 \%$ with a confidence level of $95 \%$, a power of $80 \%$, and $10 \%$ losses, the assessment would require 60 children for each group (120 for both exposed group and non-exposed group).

The study was planned to recruit 120 students, but it was carried out on 114 students after the omission of subjects whose parents refused to participate.

\section{Setting}

This research was conducted within the framework of community services applied by the National Research Centre to El-Dokki inhabitants. Children were recruited from public primary schools located in El-Dokki district nearby the National Research Centre in Giza governorate. From a list of public primary schools in this district, a representative number of public schools (4 schools) were randomly chosen. In each school, children who had any chronic disease or any disability known to affect cognitive performance or impacting behavior were excluded $[14,15]$ (e.g., children with hearing or visual defects, children with history of neonatal traumatic brain injury or meningitis, children with endocrinal diseases or hormonal disturbances, or children with mental affection or motor disability). Then, a systematic random sampling of students from grade 3 to grade 5 was performed. Every 5th student in the class list was invited to participate till the sample size was completed.

\section{Subjects}

The invited students from both sexes who accepted to participate were recruited in the study. Their ages ranged from 7.5 to 11 years old. Younger children were not included because they were unable to answer the researcher's questions in the pilot stage of this study. Similarly, older students were excluded to avoid the confounding effect of pubertal period on behavior. As well, children who had exposed to inevitable adversities were excluded (e.g., orphans).

\section{Ethical concern}

Approval by the Ethical Committees of the National Research Centre with the number (13-038), the Institute of Postgraduate Childhood Studies, and the Egyptian Ministry of Education was attained. In addition, written informed parental consents were obtained.

All children included in the study were subjected to the following.

\section{A structured questionnaire for gathering relevant personal data}

This questionnaire was filled out by the caregiver while the child was interviewed by the researcher. Data included name, age, sex, residence, maternal and paternal education and occupation, monthly income, and number of family members "for assessment of socioeconomic standard." Thorough medical, perinatal, and developmental histories were obtained.

\section{Adverse Childhood Experiences International Questionnaire}

The original Adverse Childhood Experience Questionnaire (ACE-Q) was a short rating scale designed and first published by Felitti et al. [16]. It has provided a link 
between cumulative exposure of ACEs in subjects before the age of 19 and the development of adult physical and mental health problems [16]. ACE event scores were measured for neglect, abuse (physical, sexual, and emotional), and household dysfunction. Respondents were adults, parents of children, or youth themselves. Many questionnaires have been developed after the first $\mathrm{ACE}$ questionnaire. All of them were similar in core content and scoring methods and showed consistent associations with poor health outcomes. However, important variations in results of these tools were detected due to different nationalities, cultural background, economic status, age, gender, and professional groups examined [17]. An international questionnaire was developed by the WHO (ACE_IQ). This questionnaire was field tested in seven countries (China, the Former Yugoslav Republic of Macedonia, Philippines, Thailand, Saudi Arabia, South Africa, and Vietnam). In each country, the ACE-IQ was translated including back-translation into one official language. Respondents were all aged 18 years and over. Questions cover family background, household dysfunction; physical, sexual and emotional abuse and neglect by parents or caregivers; peer violence; witnessing community violence; and exposure to war or collective violence. It was shown that most of its items were easily understood by respondents and easily delivered by interviewers. The aim of the production of this standardized international questionnaire was to reflect the range of adversity prevalence across low-, middle-, and high-income countries. ACE-IQ is being validated through trial implementation as part of broader health surveys [18].

The ACE-IQ also enables the measurement of childhood adversities in all countries and allows comparisons between them, and to assess the associations between childhood adversities and health-risk behaviors and health outcomes in later life [18]. Although ACE-IQ is considered a good standardized measure of ACEs, potential distortion of results could exist due to memory defects, as the respondent is trying to remember old events.

\section{ACE-IQ in the current study}

In the current study, authors tried to avoid the effect of memory by asking children about the current ACE using the standardized measure (ACE-IQ). Some questions concerned with marriage, work, war, and community violence were omitted from the original form to be appropriate for young age students. Arabic translation of the questionnaire with back translation was achieved by peers efficient in the English language. The questionnaire comprised 23 questions with 4 responses for each question indicating the degree of exposure. The questions' responses include never, once, few times, and many times. Exposure to one adversity is considered when the student's response is many times, except for sexual abuse. Each student was face to face interviewed to answer the questionnaire. Duration of interview ranged from 20 to $30 \mathrm{~min}$.

According to the number of adversities to which the student was exposed, subjects were classified into two groups: group A, the less exposed group including students who were exposed frequently to one or two adverse experiences, and group B, the highly exposed group including students with frequent or multiple exposure to more than three adverse experiences.

\section{Assessment of socioeconomic standard}

This was done according to the socio-economic level of the Egyptian family scale of Abd Elaziz El Shakhs [19]. It is based on parental education and occupation and family monthly income.

\section{Behavioral screening using the Pediatric Symptom Checklist-17}

PSCL was designed to facilitate the recognition of emotional and behavioral problems so that appropriate interventions can be initiated as early as possible. The PSC17 consists of 17 items that are rated by parents as "never," "sometimes," or "often" present. A value of 0 is assigned to "never," 1 to "sometimes," and 2 to "often." The total score is calculated by adding together the score for each of the 17 items. A PSC-17 score of 15 or higher suggests the presence of significant behavioral or emotional problems. Three subscales are recognized within the PSC: the PSC-17 Internalizing Subscale (cutoff score of 5 or more), the Attention Subscale (cutoff score of 7 or more), and the Externalizing Subscale (cutoff score of 7 or more) [20].

\section{Cognitive functions assessment}

Cognitive and intellectual functioning was assessed through the application of the Wechsler Intelligence Scale for Children (WISC-R), the Arabic version [21]. It is an individually administered intelligence test for children between the ages of 6 and 16 years. It is designed to assess and measure the child's verbal, performance, and full-scale IQ through assessment of different functions (short- and long-term memory, comprehension, information, abstract thinking, problem-solving, and speed of information processing).

\section{Statistical analysis}

The data was collected and analyzed on personal computer using the Statistical Package for the Social Science (SPSS) version number 18. Description of quantitative (numerical) variables is in the form of mean \pm standard deviation and range. Qualitative (nominal) variables were in the form of number and percentage. Student's $t$ test 
of 2 independent samples was used to compare 2 quantitative variables. Odds ratio was used to estimate the risk of developing abnormalities in relation to multiplicity of exposure. A $P$ value of $<0.05$ was considered significant.

\section{Results}

The study included 114 students, 61 were females (53.5\%) and 53 were males (46.5\%). Age of the students ranged from 7.5 to 11 years with a mean of $9.93 \pm 0.93$ years. Characteristics of the studied sample are shown in Table 1. The number of non-exposed students to adverse experiences was 3 students only, which represented a very small percentage of the whole sample $(2.6 \%)$. However, the rest of the study population were exposed frequently to 1 or more types of adverse experiences. Statistical analysis and comparison focused on the 2 main groups: the less exposed group (48.2 \%) (who were exposed to 1 or 2 adverse experiences) and the highly exposed group (49.1\%) (who were exposed to 3 or more adverse experiences).

The distribution of average and below-average students as regards different IQ scales is presented in Table 1. The percentages of students with affected and nonaffected behavior are shown in the same table.

The percentage distribution of exposed students to different types of adverse experiences is shown in Fig. 1. The majority of the studied sample (90.4\%) was exposed to witnessing household member treated violently, while emotional neglect appeared as the second prevalent adversity in $88.6 \%$. Sexual abuse came as the least adverse experience in $3.5 \%$ of the studied population.

There was non-significant statistical difference between both sexes as regards exposure to different types of adversities, except exposure to bullying which was more predominant in boys $(P<0.001)$ (not shown).

Median and range of PSCL scores and different IQ scales are shown in Table 2.

Table 1 Characteristics of the studied sample

\begin{tabular}{|c|c|c|}
\hline \multirow[t]{2}{*}{ Age in (years) } & Mean \pm SD & $9.39 \pm 0.93$ \\
\hline & Min.-max. & $7.58-11.0$ \\
\hline \multicolumn{2}{|l|}{ Parameter } & $N(\%)$ \\
\hline \multirow[t]{2}{*}{ Sex } & Males & $53(46.5 \%)$ \\
\hline & Females & $61(53.5 \%)$ \\
\hline \multirow[t]{5}{*}{ Socioeconomic level } & Above average & $5(4.4 \%)$ \\
\hline & Average & $9(7.9 \%)$ \\
\hline & Below average & $50(43.9 \%)$ \\
\hline & Low & $38(33.3 \%)$ \\
\hline & Very low & $12(10.5 \%)$ \\
\hline \multirow[t]{3}{*}{ Exposure to adverse experiences } & Not exposed & $3(2.6 \%)$ \\
\hline & Less exposed (1-2 adversities) & $55(48.2 \%)$ \\
\hline & Highly exposed (3 or more adversities) & $56(49.1 \%)$ \\
\hline \multirow[t]{2}{*}{ Verbal IQ } & Average & $93(81.6 \%)$ \\
\hline & Below average & $21(18.4 \%)$ \\
\hline \multirow[t]{2}{*}{ Performance IQ } & Average & $40(35.1 \%)$ \\
\hline & Below average & $74(64.9 \%)$ \\
\hline \multirow[t]{2}{*}{ Full-scale IQ } & Average & $70(61.4 \%)$ \\
\hline & Below average & $44(38.6 \%)$ \\
\hline \multirow[t]{2}{*}{ PSCL total score } & Non-affected & $60(52.2 \%)$ \\
\hline & Affected & $54(47.8 \%)$ \\
\hline \multirow[t]{2}{*}{ Attention } & Non-affected & $67(58.8 \%)$ \\
\hline & Affected & $47(41.2 \%)$ \\
\hline \multirow[t]{2}{*}{ Internalizing behavior } & Non-affected & $73(64.0 \%)$ \\
\hline & Affected & $41(36.0 \%)$ \\
\hline \multirow[t]{2}{*}{ Externalizing behavior } & Non-affected & $77(67.5 \%)$ \\
\hline & Affected & 37 (32.5\%) \\
\hline
\end{tabular}




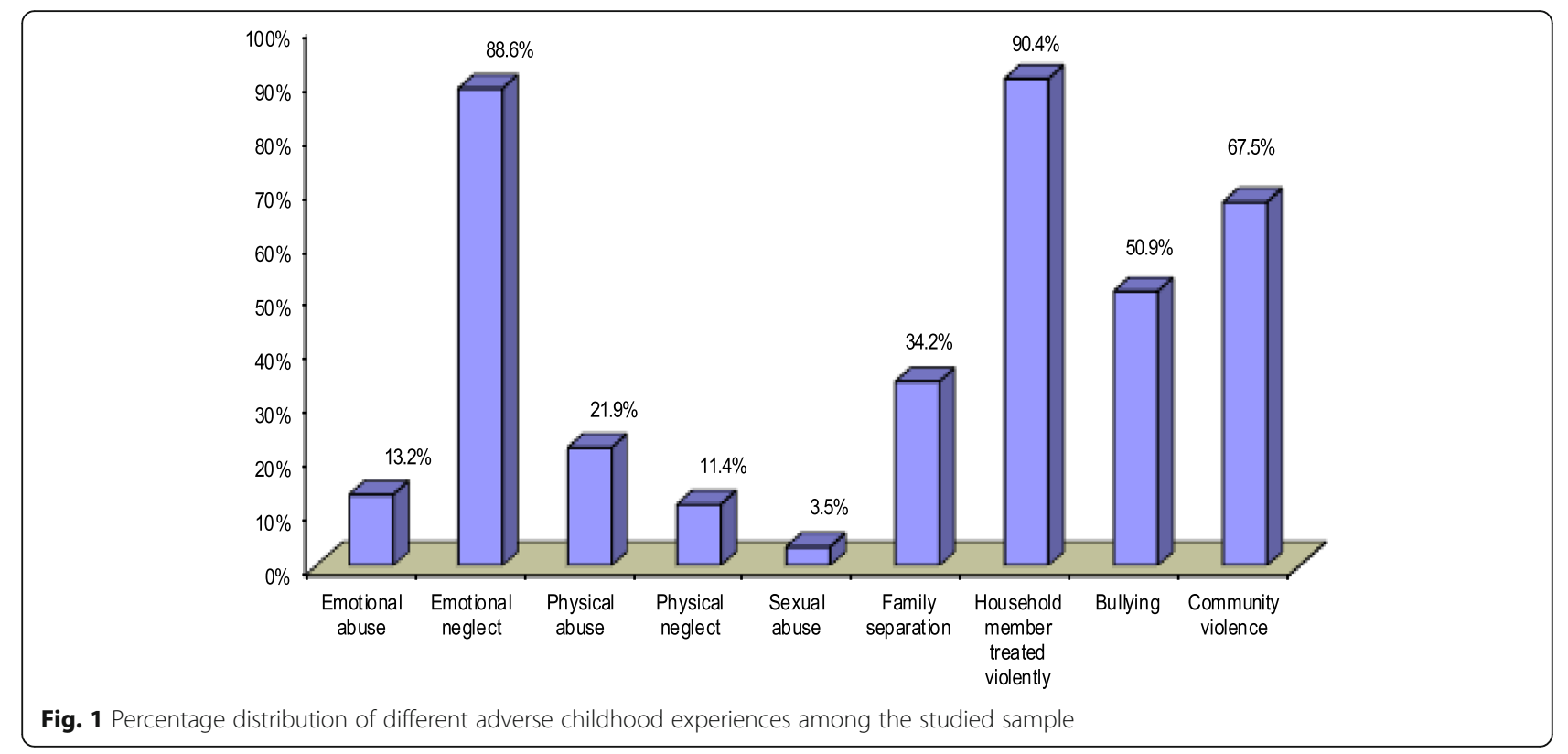

Odds ratio for the risk of below-average intelligence in relation to multiplicity of adversity exposure is shown in Table 3 . The highly exposed children are more likely to have below-average performance IQ, 2.5 times more than the less exposed group $(P=0.03)$. On the other hand, the increased odds of below-average verbal IQ and full-scale IQ in the highly exposed children do not reach a statistically significant level $(P>0.05)$.

The association between socioeconomic level and performance IQ is studied in Table 4.

No significant statistical difference could be detected on comparing means of performance IQ in different social classes. However, the highest means of performance IQ scores were recorded in students belonging to the average and above-average social levels (Table 4).

Odds ratio for the risk of behavioral troubles in relation to multiplicity of adversity exposure is presented in Table 5. The highly exposed children were nearly 3 times at risk to develop symptoms of behavioral problems more than the less exposed group $(P=0.003), 2.5$

Table 2 Median and range of different IQ scales and Pediatric Symptom Checklist scores

\begin{tabular}{ll}
\hline Parameter & Median (IQR) \\
\hline Verbal IQ & $100(94-111)$ \\
Performance IQ & $85(75-93)$ \\
Full-scale IQ & $92(83-101)$ \\
PSCL score & $14(10-20)$ \\
Attention & $6(4-8)$ \\
Internalizing behavior & $4(2-5)$ \\
Externalizing behavior & $5(3-7)$ \\
\hline
\end{tabular}

PSCL Pediatric Symptoms Checklist times more likely to develop attention deficit $(P=0.02)$, and nearly 5 times more likely to develop externalizing behavior $(P=0.0003)$. On the other hand, the highly exposed group is 1.6 times more susceptible to develop internalizing behavior more than the less exposed group, but this difference did not reach the significant level as $P>0.05$.

\section{Discussion}

Early experiences are important public health issue, as positive and negative childhood experiences have a tremendous impact on future physical and mental health [22].

The current study was conducted to test the effect of exposure to different adverse experiences in childhood on the risk of developing early behavioral and cognition abnormalities. The studied sample was chosen from public school to minimize the confounding effect of socioeconomic position on behavior and cognitive functions. They were in the pre-pubertal age to avoid the effect of puberty on psychological status. It was awful to find that all the recruited children were exposed to daily life adversities except for three. Accordingly, the researchers imposed to classify the sample into two groups according to multiplicity of adversity exposure. It was notable that witnessing household member treated violently came as the most encountered adversity with prevalence rate of $90.4 \%$, and emotional neglect was coming after by $88.6 \%$, while sexual abuse came at the last with a prevalence of $3.5 \%$. Other types of adversities encountered in this study were emotional abuse, physical abuse, physical neglect, family separation, bullying, and community violence.

In comparison to the current findings, a Brazilian study found that physical violence was the most prevailing form 
Table 3 The risk of below-average intelligence in relation to exposure to multiple adversities

\begin{tabular}{|c|c|c|c|c|c|}
\hline Exposed groups & Children with below-average IQ & Children with average IQ & OR $(95 \% \mathrm{Cl})$ & $Z$ & $P$ value \\
\hline \multicolumn{6}{|l|}{ Full-scale IQ } \\
\hline Highly exposed (56) & 24 & 32 & $1.54(0.7-3.34)$ & 1.098 & 0.272 \\
\hline Less exposed (55) & 18 & 37 & & & \\
\hline \multicolumn{6}{|l|}{ Verbal IQ } \\
\hline Highly exposed (56) & 12 & 44 & $1.39(0.53-3.63)$ & 0.682 & 0.490 \\
\hline Less exposed (55) & 9 & 46 & & & \\
\hline \multicolumn{6}{|l|}{ Performance IQ } \\
\hline Highly exposed (56) & 42 & 14 & $2.50(1.12-5.59)$ & 2.232 & $0.03^{*}$ \\
\hline Less exposed (55) & 30 & 25 & & & \\
\hline
\end{tabular}

*Significant at $P<0.05$; IQ score is considered average if it ranged 90-110 and below average if it ranged 70-89

of maltreatment, as it was encountered in $58 \%$ of investigated population, followed by neglect and psychological abuse [23]. Another study conducted in Taiwan revealed that psychological neglect was the most prevalent (69\%), followed by physical neglect $(66.5 \%)$, paternal physical abuse (15\%), maternal physical abuse (14.7\%), and sexual violence $(9.2 \%)$ [24]. There is a wide variation in the prevalence rate of different types of adversities between studies that could be explained by different cultures, varied definitions of maltreatment, using of diverse research methodologies, and varying characteristics of studied populations.

The current study hypothesized that highly exposed children to multiple adversities would perform lower than the non-maltreated group in different neurocognitive domains. Results supported this hypothesis and provided additional evidence for the growing pediatric literature linking maltreatment to neurocognitive functions. It was found that the highly exposed group was 2.5 times more likely to have below-average performance IQ than the less exposed one, while the increased odds of below-average verbal IQ and full-scale IQ did not reach significant level.

There were notable similarities between the current findings and other prior researches such as studies of De Bellis et al. [25] and Goodman et al. [26] who found that

Table 4 Mean, minimum, and maximum of performance IQ scores in different socioeconomic levels

\begin{tabular}{lll}
\hline $\begin{array}{l}\text { Socioeconomic } \\
\text { level }\end{array}$ & \multicolumn{2}{l}{ Performance IQ value } \\
\cline { 2 - 3 } & Mean \pm SD & Min.-max. \\
\hline Above average & $93.6 \pm 12.681$ & $78-111$ \\
Average & $94.33 \pm 11.99$ & $68-106$ \\
Below average & $83.08 \pm 11.168$ & $62-104$ \\
Low & $84.58 \pm 15.397$ & $65-121$ \\
Very low & $80.25 \pm 14.201$ & $65-104$ \\
$F$ & 2.308 & \\
$P$ value & 0.063 & \\
\hline
\end{tabular}

child maltreatment could be linked to global cognitive deficit, including impaired intelligence. They recorded troubles with school-based learning and a susceptibility to ongoing risk for neurodevelopmental challenges in neglected children, especially in memory and attention/ executive function. In accordance, De Bellis and Zisk [27] proved the effect of exposure to maltreatment on the growth of specific areas of the brain concerned with executive and cognitive functions such as the prefrontal cortex and cerebellum, leading to adverse cognitive development.

These findings could be explained by the persistent high level of stress hormones that harm the brain architecture, particularly in the areas that have many glucocorticoid receptors such as the prefrontal cortex, orbitofrontal cortex, amygdala, and hippocampus. Consequently, there will be alterations in their functions such as executive functions, learning, and memory [28].

Recently, Piccolo et al. [29] raised the contribution of socioeconomic standard (SES) to performance IQ. That was explained by poor stimulation and lack of access to materials and activities that favor cognitive development in families of low socioeconomic status. However, in the current study, this effect of SES was not obvious. This could be explained by the homogenous SES among the studied sample. The majority of the sample belonged to the below-average and low socioeconomic standard (77\%), and just few number of the children were from the average (7.9\%) and above average (4.4\%) levels.

On the other hand, the present study hypothesized that maltreatment during early childhood would adversely affect different psychosocial aspects. It was proved that children from the highly exposed group are 3 times at risk to develop symptoms of behavioral disorders, 2.5 times to develop inattention problems, and 5 times to develop externalizing behaviors more than the less exposed group. As regards internalizing behavior, the highly exposed group was 1.6 times at risk more than the less exposed one but this difference did not reach a significant level. 
Table 5 The risk of behavioral problems in relation to exposure to multiple adversities

\begin{tabular}{|c|c|c|c|c|c|}
\hline & Affected students & Non-affected students & OR $(95 \% \mathrm{Cl})$ & $Z$ & $P$ value \\
\hline \multicolumn{6}{|c|}{ Any behavioral abnormality } \\
\hline Highly exposed (56) & 36 & 20 & $3.32(1.51-7.24)$ & 3.006 & $0.003^{*}$ \\
\hline Less exposed (55) & 19 & 36 & & & \\
\hline \multicolumn{6}{|l|}{ Attention deficit } \\
\hline Highly exposed (56) & 30 & 26 & $2.58(1.19-5.61)$ & 2.392 & $0.02^{*}$ \\
\hline Less exposed (55) & 17 & 38 & & & \\
\hline \multicolumn{6}{|l|}{ Externalizing behavior } \\
\hline Highly exposed (56) & 28 & 28 & $5.11(2.12-12.39)$ & 3.610 & $0.000^{*}$ \\
\hline Less exposed (55) & 9 & 46 & & & \\
\hline \multicolumn{6}{|l|}{ Internalizing behavior } \\
\hline Highly exposed (56) & 24 & 32 & $1.68(0.77-3.65)$ & 1.300 & 0.193 \\
\hline Less exposed (55) & 17 & 38 & & & \\
\hline
\end{tabular}

*Significant at $P<0.05$

This was consistent with previous study of Milot et al. [30] who found a significant relation between maltreatment and development of externalizing problems in 3 to 6 years old children raised in economically disadvantaged families. In addition, Holmes et al. [31] revealed that children who were physically abused were 1.5 times more likely to demonstrate clinical levels of aggressive act relative to children who were not physically abused. The study suggested that early behavioral adaptations could determine either enhanced or disrupted behavioral functioning during later life. Intimate relationship was found between adverse childhood experiences and impairment of social functioning with increased risk of externalizing behaviors that was explained by the impacts of past experiences on emotions generation and regulation which are controlled by complex interplay between cortical and limbic brain regions [32].

In contrast with our findings, other studies documented that history of child maltreatment was significantly related to internalizing behaviors [30, 32, 33]. The masked significance of internalizing behavior in the current study could be explained by the low educational and socioeconomic level of the majority of mothers "who were the reporters of their children's behavior." These mothers usually emphasize on the most pressing symptoms such as aggressive reactions or learning problems, but when the child is introverted or depressed, he will not attract the attention of the mother as long as he or she is not a troublemaker.

As regards inattention problems and its relation to childhood adversities, our findings were matched with database analytical study of Irigaray et al. [34] that was done to evaluate the influence of child maltreatment on cognitive functioning. It showed that maltreatment during childhood had deleterious effects on attention and cognitive functioning. In the same context, Beers and De
Bellis [35] documented that maltreated children performed more poorly on measures of attention and abstract reasoning.

\section{Study limitations}

During design of the current study, researchers tried to minimize confounding variables affecting cognitive and psychosocial status. Therefore, students were recruited from public schools with nearly the same social standard, and this resulted in lack of unexposed individuals to be compared with the exposed group. The consequences of childhood adversities were studied only in relation to the number of adversities. The small sample size restricted the ability to study the effect of each type of adversities on behavior and intelligence.

\section{Conclusion}

Children exposed to multiple adverse experiences are more likely to develop behavioral problems, attention deficit, externalizing behavior, and low-performance IQ. The study highlights the need for urgent policy and intervention programs to raise the public awareness about the damaging effects of daily-life stressors on children's mental health and upcoming productivity. It is preferable in future studies to involve an un-exposed children as a control group, estimate a biological marker of chronic stress such as hair cortisol, and studying its association with cognitive and behavior consequences.

\section{Abbreviations}

ACE-IQ: Adverse Childhood Experiences International Questionnaire;

ACEs: Adverse childhood experiences; HPA: Hypothalamic pituitary adrenal; PSC-17: Pediatric Symptom Checklist-17; SES: Socioeconomic standard; WISCR: Wechsler Intelligence Scale for Children

\section{Acknowledgements}

The authors would thank all participants and their parents. 


\section{Authors' contributions}

EMS, EME, and HHE conceived and designed the experiments. AEW, SI, and AAE performed the experiments. EMS, MAS, and AAE analyzed the data. EMS, AEW, and SI contributed reagents/materials/analysis tools. EMS, MAS, and AAE were major contributors in writing the manuscript. All authors read and approved the final manuscript.

\section{Funding}

The authors have no support or funding to report.

\section{Availability of data and materials}

The datasets analyzed during the current study are available from the corresponding author on reasonable request.

\section{Ethics approval and consent to participate}

The Ethical Committees of the National Research Centre approved the study with the number (13-038). Written informed parental consents were obtained.

\section{Consent for publication}

Not applicable.

\section{Competing interests}

The authors declare that they have no competing interests.

\section{Author details}

'Department of Child Health, National Research Centre, 33 El-Bohouth Street (former El Tahrir St.), PO Box-12622, Giza, Cairo, Egypt. ${ }^{2}$ Department of Medical Physiology, National Research Centre, Giza, Cairo, Egypt. ${ }^{3}$ Medical Molecular Genetics, National Research Centre, Giza, Cairo, Egypt.

${ }^{4}$ Department of Medical Studies, Faculty of Postgraduate Childhood Studies, Ain Shams University, Cairo, Egypt.

Received: 24 July 2019 Accepted: 11 November 2019 Published online: 16 December 2019

\section{References}

1. World Health Organization (2018) Adverse childhood experiences international questionnaire. In: Adverse Childhood Experiences International Questionnaire (ACE-IQ). WHO, Geneva Available from:http://www.who.int/ violence_injury_prevention/violence/activities/adverse_childhood_exp. Cited 15 May 2019

2. Richards M, Wadsworth ME (2004) Long term effects of early adversity on cognitive function. Arch Dis Child 89(10):922-927

3. Kessler RC, McLaughlin KA, Green JG, Gruber MJ, Sampson NA, Zaslavsky AM et al (2010) Childhood adversities and adult psychopathology in the WHO World Mental Health Surveys. Br J Psychiatry 197:378-385

4. Green JG, McLaughlin KA, Berglund PA, Gruber MJ, Sampson NA, Zaslavsky AM (2010) Childhood adversities and adult psychiatric disorders in the national comorbidity survey replication I associations with first onset of DSM-IV disorders. Arch Gen Psychiatry 67:113-123

5. Cuijpers P, Smit F, Unger F, Stikkelbroek Y, Ten Have M, De Graaf R (2011) The disease burden of childhood adversities in adults: a population-based study. Child Abuse Negl 35:937-945

6. Scott KM, McLaughlin KA, Smith DAR, Ellis P (2012) Childhood maltreatment and adult DSM-IV mental disorders: comparison of prospective and retrospective findings. Br J Psychiatry 200:469-475

7. Schreier A, Wolke D, Thomas K (2009) Prospective study of peer victimization in childhood and psychotic symptoms in a nonclinical population at age 12 years. Arch Gen Psychiatry 66:527-536

8. Ladd CO, Owens MJ, Nemeroff CB (1996) Persistent changes in corticotropin-releasing factor neuronal systems induced by maternal deprivation. Endocrinology 137:1212-1218

9. Heim C, Newport DJ, Bosnal R, Miller AH, Nemeroff CB (2001) Altered pituitary-adrenal axis responses to provocative challenge tests in adult survivors of childhood abuse. Am J Psychiatry 158:575-581

10. Duman RS (2009) Neuronal damage and protection in the pathophysiology and treatment of psychiatric illness: stress and depression. Dialogues Clin Neurosci 11:239-255

11. Chapman DP, Whitfield CL, Felitti VJ, Dube SR, Edwards VJ, Anda RF (2004) Adverse childhood experiences and the risk of depressive disorders in adulthood. J Affect Disord 82(2):217-225
12. Carpenter LL, Tyrka AR, Ross NS, Khoury L, Anderson GM et al (2009) Effect of childhood emotional abuse and age on cortisol responsivity in adulthood. Biol Psychiatry 75:66-69

13. Vanaelst B, Huybrechts I, De Bourdeaudhuij I, Bammann K, Hadjigeorgiou C, Eiben G et al (2012) Prevalence of negative life events and chronic adversities in European pre- and primary-school children: results from the IDEFICS study. Arch Public Health 70:26

14. Elzaree FA, Shehata MA, El Wakeel MA, El-Alameey IR, AbuShady MM, Helal SI (2018) Adaptive functioning and psychosocial problems in children with beta thalassemia major. Open Access Maced J Med Sci 6(12):2337-2341

15. El-Alameey IR, Alzaree F, Shehata MA, Shady MMA, Atti MA, El-Khonezy MI (2019) Neurocognitive function and its related potentials in children with beta thalassemia major: an Egyptian study. Open Access Maced J Med Sci 7(3):322-328

16. Felitti VJ, Anda RF, Nordenberg D, Williamson DF, Spitz AM, Edwards V et al (2019) Relationship of childhood abuse and household dysfunction to many of the leading causes of death in adults: the Adverse Childhood Experiences (ACE) Study. Am J Prev Med 56(6):774-786

17. Bethell CD, Carle A, Hudziak J, Gombojav N, Powers K, Wade R, Braveman P (2017) Methods to assess adverse childhood experiences of children and families: toward approaches to promote child well-being in policy and practice. Acad Pediatr 17(7):S51-S69

18. WHO (2011) Adverse childhood experiences international questionnaire, pilot study review and finalization meeting. WHO Headquarters, Geneva Available from https://www.who.int/violence_injury_prevention/violence/ activities/adverse_childhood_experiences/global_research_network_may_2 011.pdf. Cited 12 Apr 2016

19. El-Shakhs AE (2013) Social level and the economic scale of the family: the scale manual, 2nd edn. Anglo-Egyptian library, Cairo

20. Gardner W, Murphy M, Childs G (1999) The PSC-17: a brief pediatric symptom checklist including psychosocial problem subscales: a report from PROS and ASPN. Ambul Child Health 5:225-236

21. Ismaiel E, Kamel M (1999) Wechsler intelligence scale for children revised, Arabic version, 7th edn. El-Nahda El Massryia, Cairo

22. Center for Disease Control and Prevention (2016) Adverse childhood experiences. Available from https://www.cdc.gov/violenceprevention/ childabuseandneglect/acestudy/index.html. Cited 12 Apr 2016

23. Brito AMM, Zanetta DMT, Mendonça RCV, Barison SZP, Andrade VAG (2005) Violência doméstica contra crianças e adolescentes: Estudo de um programa de intervenção. Cien Saude Colet 10(1):143-149

24. Hsieha YP, Tao Shenb AC, Weic HS, Fengd JY, Huange SCY, Hwaf HL (2016) Associations between child maltreatment, PTSD, and internet addiction among Taiwanese students. Comput Hum Behav 56:209-214

25. De Bellis M, Hooper SR, Spratt EG, Woolley DP (2009) Neuropsychological findings in childhood neglect and their relationships to pediatric PTSD. J Int Neuropsychol Soc 15(6):868-878

26. Goodman GS, Quas JA, Ogle CM (2010) Child maltreatment and memory. Annu Rev Psychol 61:325-351

27. De Bellis MD, Zisk AAB (2014) The biological effects of childhood trauma. Child Adolesc Psychiatr Clin N Am 23(2):185-222

28. National Scientific Council on the Developing Child. (2011) Building the brain's "air traffic control" system: how early experiences shape the development of executive function. (Working paper 11). Available from https://developingchild.harvard.edu/wp-content/uploads/2011/05/HowEarly-Experiences-Shape-the-Development-of-Executive-Function.pdf. Cited 15 Mar 2016

29. Piccolo Da Rosa L, Arteche AX, Fonseca RP, Grassi-Oliveria R, Salles JF (2016) Influence of family socioeconomic status on $1 \mathrm{Q}$, language, memory and executive functions of Brazilian children. Psicol. Refl. Crít. 29, 23(2016) https://doi.org/10.1186/s41155-016-0016-x

30. Milot T, Éthier LS, St-Laurent D, Provost MA (2010) The role of trauma symptoms in the development of behavioral problems in maltreated preschoolers. Child Abuse Negl 34(4):225-234

31. Holmes MR, Yoon S, Voith LA, Kobulsky JM, Steigerwald S (2015) Resilience in physically abused children: protective factors for aggression. Behav Sci 5: 176-189

32. Dvir Y, Frod JD, Hill M, Frazier JA (2014) Childhood maltreatment, emotional dysregulation, and psychiatric comorbidities. Harv Rev Psychiatry 22(3):149-161

33. Lewis TL, Kotch J, Wiley TR, English DJ, Thompson R, Zolotor AJ, Block SD, Dubowitz H (2011) Internalizing problems: a potential pathway from child maltreatment to adolescent smoking. J Adolesc Health 48(3):247-252 
34. Irigarayl TQ, Pachecoll JB, Grassi-Oliveiral R, Fonsecal RP, De Carvalho JC, Kristensenl CH (2013) Child maltreatment and later cognitive functioning: a systematic review. Psicol Reflex Crít 26(2):376-387

35. Beers SR, De Bellis MD (2002) Neuropsychological function in children with maltreatment-related posttraumatic stress disorder. Am J Psychiatry 159(3): 483-486

\section{Publisher's Note}

Springer Nature remains neutral with regard to jurisdictional claims in published maps and institutional affiliations.

\section{Submit your manuscript to a SpringerOpen ${ }^{\circ}$ journal and benefit from:}

- Convenient online submission

- Rigorous peer review

- Open access: articles freely available online

- High visibility within the field

- Retaining the copyright to your article

Submit your next manuscript at $\boldsymbol{\wedge}$ springeropen.com 